\title{
Design rules of pseudocapacitive electrode materials: ion adsorption, diffusion, and electron transmission over prototype $\mathrm{TiO}_{2}$
}

\author{
Lijing Wang ${ }^{1 \dagger}$, Xiaolong Yao ${ }^{1 \dagger}$, Da Chen ${ }^{2}$, Jin Wang ${ }^{1}$, Zhenzhou Zhang ${ }^{1}$, Jieyu Liu ${ }^{1}$, Tianquan Lin $^{3}$, \\ Wei-Hua Wang ${ }^{1}$, Zhanglian Hong ${ }^{4}$, Fuqiang Huang ${ }^{3}$ and Weichao Wang ${ }^{*}$
}

\begin{abstract}
The development of a high-performing pseudocapacitor requires a comprehensive understanding of electrode materials from the aspects of electron transfer and electrolyte ion adsorption and diffusion. Herein, these factors are considered over the prototype $\mathrm{TiO}_{2}$, and a high pseudocapacitance is achieved via the introduction of various defects, i.e., oxygen defect $\left(V_{O}\right)$ and co-doped defect $\left(V_{O}+N_{O}\right)$. The study is based on joint explorations of first-principle calculations and the transfer matrix method. Relative to pristine $\mathrm{TiO}_{2}\left(300 \mathrm{~F} \mathrm{~g} \mathrm{~g}^{-1}\right)$, defective $\mathrm{TiO}_{2}$ produces pseudocapacitance as high as $1700 \mathrm{~F} \mathrm{~g}^{-1}$. Moreover, defects induce small barriers for electron transmission caused by surface band bending. The climbing image nudged elastic band diffusion of $\mathrm{H}$ ions displays a much higher barrier in $\mathrm{TiO}_{2}-\mathrm{V}_{\mathrm{O}}$ than in $\mathrm{TiO}_{2}-\mathrm{V}_{\mathrm{O}}+\mathrm{N}_{\mathrm{O}}$. Such a result indicates easy $\mathrm{H}$ diffusion in the co-doped system. This work provides insights into the adsorption and diffusion of electrolyte ions and the influence of defects on electron transfer. The results are also significant for the design and optimization of electrode materials for the next generation of supercapacitors.
\end{abstract}

Keywords: pseudocapacitance, charge storage, ion diffusion, electron transmission

\section{INTRODUCTION}

Pseudocapacitor continues to gain attention in applications of energy storage and conversion systems because of its high energy density and power density [1-7]. Pseudocapacitance is largely determined by the properties of the electrode materials $[2,8]$. In the development of highly efficient pseudocapacitive electrode materials, a full picture of electron transfer, electrolyte ion adsorption, and diffusion on electrode materials should be considered simultaneously. For electron transfer, the transfer coefficient is governed by the tunneling barrier and results from the conduction band $(\mathrm{CB})$ bending $[9,10]$ of the electrode materials when exposed to aqueous environments. The reduction of the transfer barrier requires minimal $\mathrm{CB}$ bending, which is principally achieved through the introduction of considerable amounts of defects. For electron transfer, no barrier induced by band bending forms in metallic electrode materials. From the aspect of ions, ion adsorption determines the charge storage capability. Moreover, ion diffusion from the top surface to sublayers is of great significance as the diffusion barrier controls the feasibility of ion travel. Specifically, a relatively low ion diffusion barrier increases the amount of hydrogen ions on the surface and sublayers of the electrode. In sum, existing materials rarely meet all the aforementioned requirements. Therefore, material modifications must be made to achieve high pseudocapacitance.

Transition metallic oxides (TMOs) $[4,11]$ are potential semiconductor electrode material candidates because of their unique behavior of localizing d-orbitals around the Fermi level $\left(E_{\mathrm{F}}\right)$ of electronic structures. Among the $\mathrm{TMOs}, \mathrm{TiO}_{2}$ shows great promise because of its ultra-hydrophilic property [12], high chemical stability [13], flexibility in creating defects $[14,15]$, and so on. However, pristine $\mathrm{TiO}_{2}$ exhibits semiconducting behavior and low density of states around $E_{\mathrm{F}}$ with a large bandgap of $\sim 3 \mathrm{eV}$ [16]. For intrinsic $\mathrm{TiO}_{2}$, the high Schottky potential barrier and low carrier concentration inhibit electron carrier transport at the interface of aqueous materials. Therefore, pristine $\mathrm{TiO}_{2}$ cannot be easily considered a promising pseudocapacitive material.

Material modifications are desirable to achieve $\mathrm{TiO}_{2}$-based pseudocapacitors. For instance, defective black $\mathrm{TiO}_{2}$ nanotube arrays show a capacitance of $168 \mathrm{mF} \mathrm{cm}{ }^{-2}$, which is over 30 times that of pure samples [17]. On the one hand, the pseudocapacitive charge storage is confirmed by the valence state changes of $\mathrm{Ti}^{3+} / \mathrm{Ti}^{4+}$ obtained by X-ray photoelectron spectroscopy (XPS) analysis for the redox reaction; on the other hand, the surface amorphous layer induced by surface-confined protonation/deprotonation is measured using high-resolution transmission electron microscopy. Wang et al. [18] further introduced co-dopant $\mathrm{V}_{\mathrm{O}}$ and substitutional $\mathrm{N}$ on $\mathrm{O}$ sites and achieved higher capacitance $\left(210 \mathrm{Fg}^{-1}\right)$ than that of the oxygen vacant sample. Huang et al. [19] prepared amorphous defective $\mathrm{TiO}_{2}$ that achieved a capacitance as high as $\sim 1800 \mathrm{Fg}^{-1}$. Despite the extensive experimental investigations [17-22], the role of

\footnotetext{
${ }^{1}$ Integrated Circuits and Smart System Lab (Shenzhen), Renewable Energy Conversion and Storage Center, Tianjin Key Laboratory of Photo-Electronic Thin Film Device and Technology, College of Electronic Information and Optical Engineering, Nankai University, Tianjin 300071, China

${ }^{2}$ Key Laboratory of Civil Aviation Thermal Hazards Prevention and Emergency Response, Civil Aviation University of China, Tianjin 300300, China

${ }^{3}$ CAS Key Laboratory of Materials for Energy Conversion and State Key Laboratory of High Performance Ceramics and Superfine Microstructure, Shanghai Institute of Ceramics, Chinese Academy of Sciences, Shanghai 200050, China

${ }^{4}$ State Key Laboratory of Silicon Materials, School of Materials Science and Engineering, Zhejiang University, Hangzhou 310027, China

$\dagger$ These authors contributed equally to this work.

* Corresponding author (email: weichaowang@nankai.edu.cn)
} 
defects in $\mathrm{TiO}_{2}$ to produce pseudocapacitance remains unclear. The rapid development of TMOs' pseudocapacitance could thus be restricted by factors such as carrier electron transmission, ion adsorption and diffusion, etc., which are not considered in material design.

In the current work, we adopted a well-studied $\mathrm{TiO}_{2}$ electrode material to demonstrate the comprehensive evaluation and tuning of the capacitance of $\mathrm{TiO}_{2}$ structures, from pristine to defective ones, on the basis of the aforementioned aspects and by applying first-principle calculations and the transfer matrix method (TMM) [23]. On the (101) surface [24] of the anatase phase $\mathrm{TiO}_{2}$, two defective structures $\left(\mathrm{TiO}_{2}-\mathrm{V}_{\mathrm{O}}\right.$ and $\mathrm{TiO}_{2}-\mathrm{V}_{\mathrm{O}}$ $+\mathrm{N}_{\mathrm{O}}$ ) along with a pristine lattice were considered for the pseudocapacitance through rigid band approximation (RBA) $[25,26]$. The two defective $\mathrm{TiO}_{2}$ structures were found to lead to a high density of states around $E_{\mathrm{F}}$ and thus resulted in ultrahigh capacitance values greater than $1400 \mathrm{Fg}^{-1}$, which are five times that of pristine $\mathrm{TiO}_{2}$. Furthermore, both types of defects caused $E_{\mathrm{F}}$ pinning and could largely avoid $\mathrm{CB}$ bending. The $\mathrm{V}_{\mathrm{O}}+\mathrm{N}_{\mathrm{O}}$ defect assisted in the high $\mathrm{H}$ diffusion by reducing the $\mathrm{H}$ diffusion barrier. In sum, the $\mathrm{TiO}_{2}$ structure with $\mathrm{V}_{\mathrm{O}}+\mathrm{N}_{\mathrm{O}}$ showed great promise as a pseudocapacitive electrode material after the consideration of all the proposed requirements. This work offers comprehensive insights into pseudocapacitive material design in terms of electrolyte ion adsorption and diffusion and electron transfer on electrode materials.

\section{CALCULATION MODELS AND METHOD}

The Vienna $a b$ initio simulation package [27] was used for the density functional theory calculations. The exchange correlation energy was developed by the plane wave base vector and processed by the Perdew-Burke-Ernzerhof scheme in the generalized gradient approximation [28]. The electronic structure was calculated using the spatial nonlocal hybrid density functional HSE06 [29]. Cutoff energy of $400 \mathrm{eV}$ was employed, and the convergence criteria of the force and energy were set to be $0.02 \mathrm{eV} \AA^{-1}$ and $10^{-5} \mathrm{eV}$, respectively. $k$ points with a density of 2 $\times 6 \times 1$ in the Brillouin zone were produced by the $\Gamma$ centered Monhkorst-Pack grid. A vacuum layer of $15 \AA$ was used in all the slab structures to prevent periodical interactions between the top and bottom surfaces (Table S1). The $1 \times 1$ anatase (101) surface supercell was constructed with three $\mathrm{TiO}_{2}$ atomic layers (36 atoms), and the bottom $\mathrm{TiO}_{2}$ layer was frozen to simulate the bulk bonding properties (Table S2). The charge calculation was obtained from the Bader charge analysis [30,31]. The transition state of hydrogen migration was determined by the climbing image nudged elastic band (CI-NEB) method [32]. Different oxygen vacancy concentrations were achieved by enlarging the size of the supercell. The oxygen vacancy concentrations of $2.78 \%, 1.39 \%, 0.93 \%, 0.69 \%$, and $0.46 \%$ corresponded to the $1 \times$ $1,1 \times 2,1 \times 3,1 \times 4$, and $2 \times 3$ supercells, respectively.

The binding energy of hydrogen ion adsorption $\left(E_{\mathrm{b}}\right)$ is calculated by

$E_{\mathrm{b}}=E_{\mathrm{tot}}-E_{\mathrm{TiO}_{2}}-\mu_{\mathrm{H}}$,

where $E_{\mathrm{TiO}_{2}}$ and $E_{\text {tot }}$ are the energies of the systems before and after hydrogen adsorption, respectively; and $\mu_{\mathrm{H}}$ is the energy of the $\mathrm{H}$ atom. The formula of defect formation energy is

$E_{\text {form }}=E_{\text {defective }}-E_{\text {pristine }}+\mu_{\mathrm{O}}-\mu_{\mathrm{N}}$,

where $E_{\text {defective }}$ and $E_{\text {pristine }}$ are the total energies of the defective and pristine $\mathrm{TiO}_{2}$, respectively; and $\mu_{\mathrm{O}}$ and $\mu_{\mathrm{N}}$ are the chemical potentials of the oxygen and nitrogen atoms, respectively. The range for the chemical potential of oxygen is determined from the O-rich condition $\left(\mu_{\mathrm{O}}=\mu_{\mathrm{O}_{2}} / 2\right)$ to the O-poor condition $\left(\mu_{\mathrm{O}}=\right.$ $\left.\left(\mu_{\mathrm{TiO}_{2}}-\mu_{\mathrm{Ti}}\right) / 2\right) ; \mu_{\mathrm{Ti}}$ represents the chemical potential of bulk Ti. The chemical potential of $\mathrm{N}$ is considered between the $\mathrm{N}$-rich $\left(\mu_{\mathrm{N}}=\mu_{\mathrm{N}_{2}} / 2\right)$ and N-poor conditions $\left(\mu_{\mathrm{N}}=\mu_{\mathrm{TiN}}-\mu_{\mathrm{Ti}}\right)$.

The transfer coefficient of electron tunneling through the barrier induced by the CB bending of the surface of $\mathrm{TiO}_{2}$ was calculated using TMM [23]. Owing to the variant band barrier in the space charge region, solving the Schrodinger equation directly would be difficult. Hence, we utilized TMM to deal with the arbitrary potential term in the Hamiltonian, which enables the division of arbitrarily continuous potential $v$ s. distance into numerous small rectangle potentials (Fig. 1) so that the Schrodinger equation could be solved analytically within each piece of divided potential. Then, the continuous boundary was applied to combine all the divided pieces and essentially deliver the whole electron tunneling coefficient (Fig. 1) (further details are available in our previous publication [23]).

\section{RESULTS AND DISCUSSION}

\section{Structural properties of pristine and defective $\mathrm{TiO}_{2}$}

The bulk anatase $\mathrm{TiO}_{2}$ has a tetragonal structure with a space group $I 4_{1} /$ amd. By combining this symmetry and the low-index surface energies, we constructed the (101) surface herein. The lattice constants after relaxation were $a=10.443 \AA$ and $b=3.806 \AA$, starting from the optimized bulk lattice constants $a$ $=b=3.784 \AA$ and $c=9.534 \AA$; this result was consistent with the experimental value [33]. For $\mathrm{TiO}_{2}$, an oxygen vacancy is one of the major defects under Ti-rich synthesis conditions [34]. To mimic the natural n-type defect of $\mathrm{TiO}_{2}$, we introduced oxygen vacancy and substitutional $\mathrm{N}$. We labeled the oxygen sites with numbers so that they can easily be recognized in the succeeding

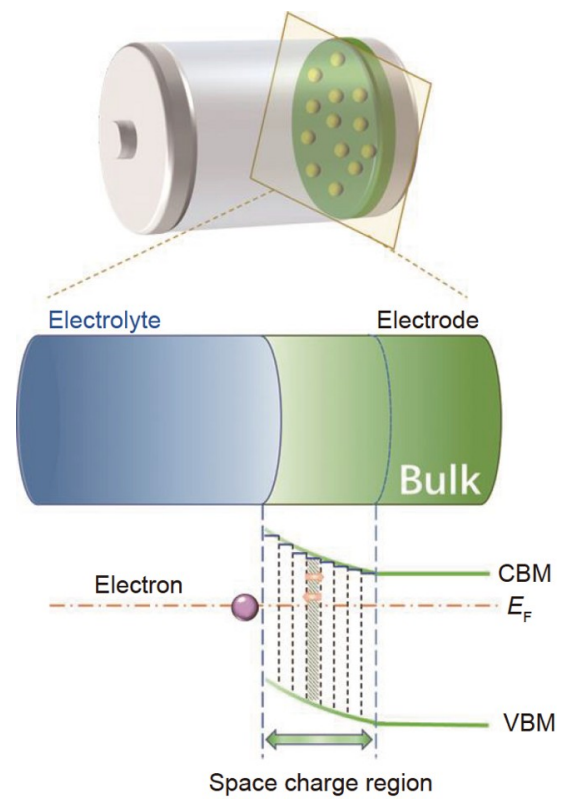

Figure 1 Energy band diagrams of semiconductor and electrolyte contacts. The blue line represents the potential barrier of each small rectangle divided in the space charge region. CBM and VBM represent the conduction band minimum and valence band maximum, respectively. 
analysis (Fig. 2a). To comprehensively examine the defects in $\mathrm{TiO}_{2}$, we considered four typical defective configurations: one oxygen vacancy $\left(\mathrm{V}_{\mathrm{O}}\right)$, one substitution $\mathrm{N}\left(\mathrm{N}_{\mathrm{O}}\right)$, two oxygen vacancies $\left(2 \mathrm{~V}_{\mathrm{O}}\right)$, and one oxygen vacancy coexisting with substitutional $\mathrm{N}\left(\mathrm{V}_{\mathrm{O}}+\mathrm{N}_{\mathrm{O}}\right)$. For each defect case, we calculated all the possible configurations and adopted only the most stable structure for further analysis.

Specifically, the oxygen vacancy $\mathrm{V}_{\mathrm{O} 9}$ located in the subsurface layer was the most stable oxygen vacancy configuration (Fig. 2b). This location was in good accordance with the reported site $[35,36]$. Our calculations showed that the stable position of $\mathrm{N}_{\mathrm{O}}$ was also at position $\mathrm{O} 9$ in Fig. 2a (Table S3). On the basis of $\mathrm{V}_{\mathrm{O}}$, one $\mathrm{O}$ atom was replaced with an $\mathrm{N}$ atom to obtain the complex defect $\mathrm{V}_{\mathrm{O}}+\mathrm{N}_{\mathrm{O}}$. The stable site of the substitutional $\mathrm{N}$ was at $\mathrm{O} 7$ (Table S4). Intuitively, this $\mathrm{N}_{\mathrm{O}}$ site emerged from the unsaturated $\mathrm{Ti}$ bonds in the presence of the neighboring oxygen vacancy. Therefore, the relatively strong interaction between $\mathrm{N}$ and $\mathrm{Ti}$ made the structure increasingly stable, as confirmed by the short Ti-N bond length $\left(d_{\mathrm{Ti}-\mathrm{N}}=1.938 \AA, d_{\mathrm{Ti}-\mathrm{O}}=1.964 \AA\right)$ and negative charge state $(\mathrm{N}:-1.31, \mathrm{O}:-1.16)$. Furthermore, we considered a high oxygen defect concentration of $2 \mathrm{~V}_{\mathrm{O}}$. On the basis of the one oxygen vacancy configuration, an additional oxygen vacancy was created at the $\mathrm{O} 8$ site (Fig. S1).

To evaluate the feasibility of the surfaces with the aforementioned defects, we calculated the formation energy $v s$. oxygen chemical potential under the $\mathrm{N}$-rich condition (the calculation details are available in the CALCULATION MODELS AND METHOD section); and the results are shown in Fig. 2c. The results for the $\mathrm{N}$-poor condition are provided in the Supplementary Information (Fig. S2). In the O-rich condition, $\mathrm{V}_{\mathrm{O}}$ showed the highest stability. As the oxygen partial pressure decreased, i.e., O-poor condition, $\mathrm{V}_{\mathrm{O}}+\mathrm{N}_{\mathrm{O}}$ showed the highest stability. As the two types of defects are energetically favorable, we adopted them to explore the origin of the pseudocapacitance in the following sections.

Upon the (101) surfaces, the adsorption of hydrogen ions was simulated to mimic the acid electrolyte condition (Fig. S3). Take the total energy of $\mathrm{H}$ adsorption at the $\mathrm{O} 2$ location as the reference energy. The total energy with $\mathrm{H}$ located from the vacuum to the sublayers was calculated accordingly (Fig. 2d). In a vacuum, $\mathrm{H}$ formed no bonds with the surface, and the total energy was thus $2.5 \mathrm{eV}$ higher than that of the reference. As $\mathrm{H}$ was located in the first $(\mathrm{O} 4, \mathrm{O} 5)$, second $(\mathrm{O} 8)$, and third layers (O16) on the pristine surface, the energy increased up to 0.84 , 0.68 , and $0.97 \mathrm{eV}$, respectively. Additionally, hydrogen tended to fill the site of oxygen vacancy in the vacant models. As the binding energies of $\mathrm{H}$ adsorption were all negative (Fig. 2), the structures were thermodynamically stable. These energy differences among different sublayers actually reflected the feasibility of $\mathrm{H}$ diffusion from the top to the sublayers.

\section{Electronic property variations among different defect configurations}

The electronic structure essentially determines the conductivity of materials, which is of great significance for the application of electrodes. To explore the conductivity of pristine and defective
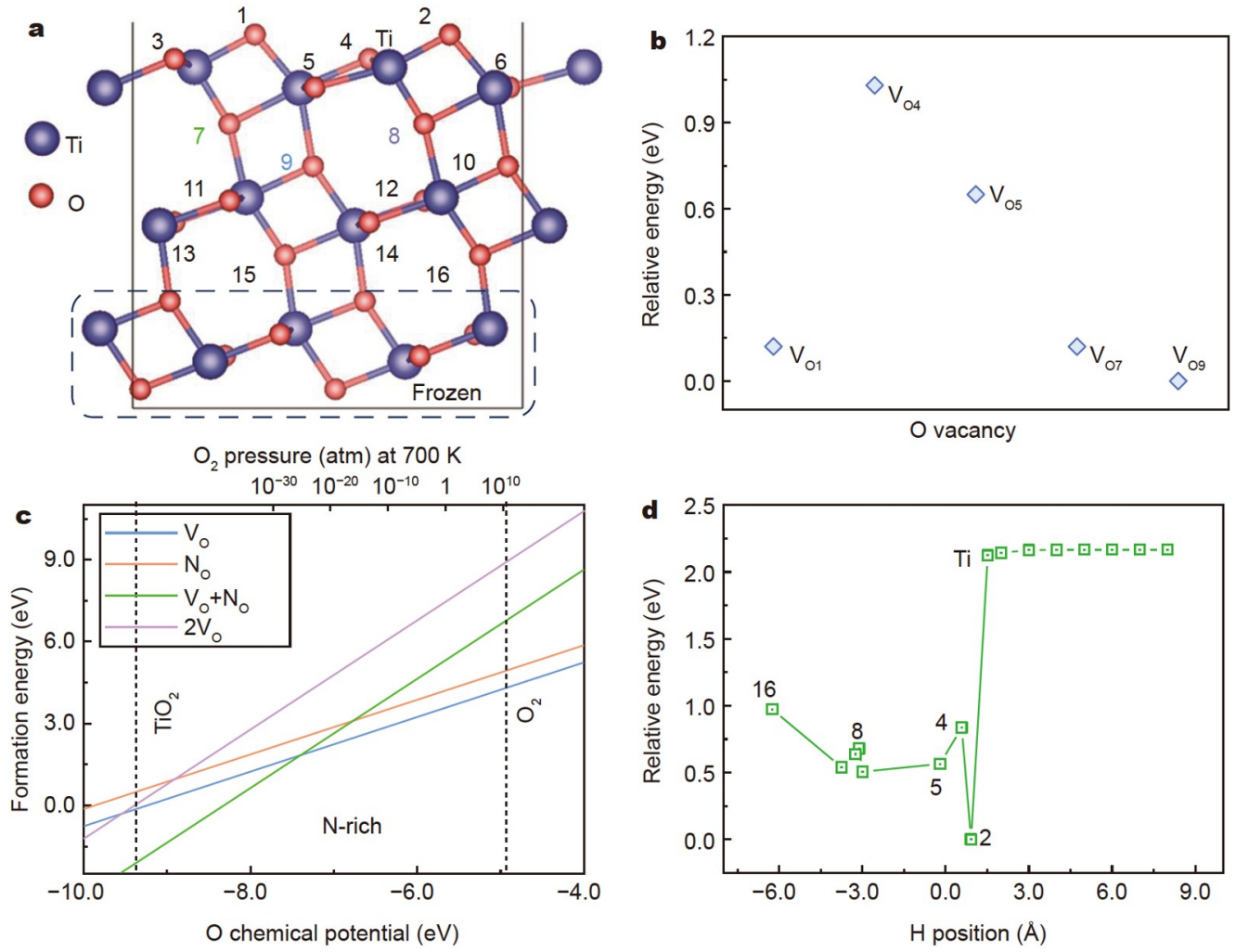

Figure 2 Structure and defective formation energy of $\mathrm{TiO}_{2}$. (a) Side view of $\mathrm{TiO}_{2}(101)$ in anatase phase. The numbers represent different oxygen sites. The blue 9, green 7 , and purple 8 represent the sites of one $\mathrm{O}$ vacancy in $\mathrm{V}_{\mathrm{O}}$, the substitutional $\mathrm{N}$ in $\mathrm{V}_{\mathrm{O}}+\mathrm{N}_{\mathrm{O}}$, and the second $\mathrm{O}$ vacancy in $2 \mathrm{~V}_{\mathrm{O}}$, respectively. (b) Relative energy of $\mathrm{V}_{\mathrm{O}}$ configurations. $\mathrm{V}_{\mathrm{ox}}$ is the oxygen vacancy labeled as $x$. (c) Defect formation energies of $\mathrm{TiO}_{2}$ under different oxygen chemical potentials. (d) Energy of one $\mathrm{H}$ migrating from the vacuum to $\mathrm{TiO}_{2}$ relative to that of the $\mathrm{H}$ adsorbed on the surface. The numbers represent the $\mathrm{H}$ adsorption sites based on Fig. 2a. 
$\mathrm{TiO}_{2}$, we calculated the electronic density of states (Fig. 3).

We found that the pristine $\mathrm{TiO}_{2}$ (Fig. 3a) surface was semiconductive with a large bandgap $(3.30 \mathrm{eV})$ and was free from surface states (Figs S4 and S5). The surface Ti and O atoms were saturated and thus led to the absence of gap states. The VBM was aligned up at $0 \mathrm{eV}$ on the basis of the projected density of states (PDOSs), as shown in Fig. 3. We should note that the occupied states of pristine $\mathrm{TiO}_{2}$ were dominated by the $\mathrm{O} 2 \mathrm{p}$ orbital and that the empty states were mainly composed of Ti $3 \mathrm{~d}$ states. As reported, the introduction of defects results in impurity levels for different defect types and concentrations. Varying oxygen vacancy concentrations would tune the locations of the shallow defect levels in the upper region of the bandgap region because of $E_{\mathrm{F}}=E_{\mathrm{i}}+k_{0} T \ln \left(N_{\mathrm{D}} / n_{i}\right)$, where $k_{0}$ is the Boltzmann constant; $T$ is the temperature; $N_{\mathrm{D}}$ and $n_{\mathrm{i}}$ are the $\mathrm{n}$ type doped carrier concentration and intrinsic carrier concentration, respectively. For the defective configurations, $E_{\mathrm{F}}$ was pinned in the gap states contributed by the $\mathrm{Ti} 3 \mathrm{~d}$ orbitals. Additionally, the apparent discrepancy of states below the CBM was observed in the two defective $\mathrm{TiO}_{2}$ (Figs S6 and S7), that is, a locally sharp peak (Fig. 3b) and continuous lower states (Fig. 3c) in $\mathrm{TiO}_{2}-\mathrm{V}_{\mathrm{O}}$ and $\mathrm{TiO}_{2}-\mathrm{V}_{\mathrm{O}}+\mathrm{N}_{\mathrm{O}}$, respectively. Owing to the n-type doping of the oxygen vacancy, the dangling bond of the unsaturated $\mathrm{Ti}$ atoms contributed to the impurity states. As shown in Fig. 3b, the defect states in $V_{O}$ were highly localized and led to the peak with a large intensity. By contrast, the sharp impurity level disappeared, and the continuous states became dominant below the CBM; this result was consistent with reported findings

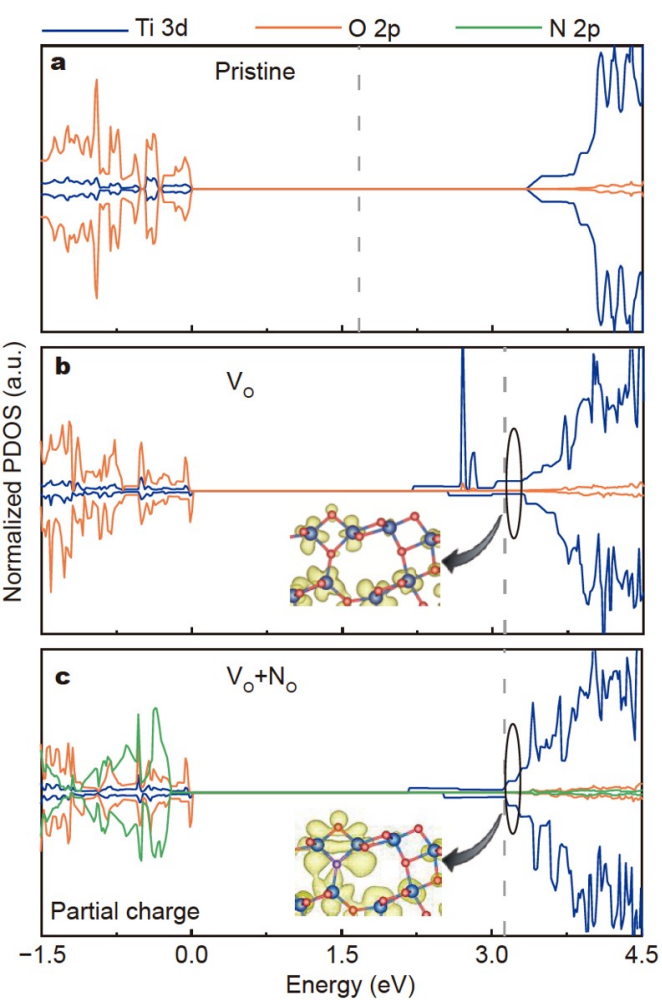

Figure 3 Density of states and partial charge densities of $\mathrm{TiO}_{2}$. Normalized PDOSs for $\mathrm{Ti}, \mathrm{O}$, and $\mathrm{N}$ atoms of (a) pristine $\mathrm{TiO}_{2}$, (b) $\mathrm{TiO}_{2}$ with one oxygen vacancy $\left(\mathrm{V}_{\mathrm{O}}\right)$, and $(\mathrm{c}) \mathrm{TiO}_{2}$ with one oxygen vacancy and one substitutional nitrogen $\left(\mathrm{V}_{\mathrm{O}}+\mathrm{N}_{\mathrm{O}}\right)$. The gray dotted line represents the Fermi level. The partial charge densities of $\mathrm{V}_{\mathrm{O}}$ and $\mathrm{V}_{\mathrm{O}}+\mathrm{N}_{\mathrm{O}}$ are within $0.1 \mathrm{eV}$ above the $E_{\mathrm{F}}$ (isosurface $=0.007$ e $\AA^{-3}$ ).
[37]. The conductivity $(\sigma)$ of materials is known to be determined by the density $(n)$, lifetime $(\tau)$, and effective mass $\left(m^{*}\right)$ of the carrier according to the formula $\sigma=n q^{2} \tau / m^{*}$. Hence, the introduction of defects, i.e., $\mathrm{V}_{\mathrm{O}}$ and $\mathrm{V}_{\mathrm{O}}+\mathrm{N}_{\mathrm{O}}$, certainly increased the electron concentration. Moreover, the ionized acceptor $\mathrm{N}$ weakened the electron capture effect and thus improved the electron transfer.

To further explore the effects of the defects on the electron transport of $\mathrm{TiO}_{2}$, we investigated the charge distributions of the $\mathrm{V}_{\mathrm{O}}$ and $\mathrm{V}_{\mathrm{O}}+\mathrm{N}_{\mathrm{O}}$ structures within $0.1 \mathrm{eV}$ above the $E_{\mathrm{F}}$ (Fig. $3 \mathrm{~b}, \mathrm{c}$ ). With the same partial charge isosurface values, the partial charge was more continuous in the system with $\mathrm{V}_{\mathrm{O}}+\mathrm{N}_{\mathrm{O}}$ than in the system with $\mathrm{V}_{\mathrm{O}}$ from the $\mathrm{TiO}_{2}$ atomic layer to the sublayers. The partial charge of $\mathrm{TiO}_{2}-\mathrm{V}_{\mathrm{O}}$ was discrete and detrimental to the charge transfer during the surface redox reactions.

Combining the electronic structures and the partial charge distributions, we found that the systems with defects were more suitable as electrode material candidates than the pristine $\mathrm{TiO}_{2}$. More specifically, the introduction of the complex point defects $\mathrm{V}_{\mathrm{O}}+\mathrm{N}_{\mathrm{O}}$ led to the continuous states below the CBM. This result indicated the great potential applications of such defective structure to the electrode of capacitor from the charge transport point of view.

\section{Pseudocapacitance of $\mathrm{TiO}_{2}$ from the aspect of $\mathrm{H}$ adsorption}

Pseudocapacitance is basically determined by two factors, i.e., charge transfer amount and variation of voltage during the charge and discharge processes. For the former case, the Bader charge scheme is widely utilized to obtain the charge difference before and after electrolyte ion adsorption. However, conflicts occur in calculating the voltage change during the charge and discharge cycles $[38,39]$ as the band variations are not considered during the charge and discharge process. In fact, our previous study [25] on $\mathrm{Ti}_{3} \mathrm{C}_{2} \mathrm{~T}_{2}$ electrode materials showed that the shape of band structures is not visibly altered in the charging process with various amounts of charging electrons and that only the position of $E_{\mathrm{F}}$ changes. Therefore, we adopted the RBA to reasonably calculate the voltage change after $\mathrm{H}$ ion adsorption herein. Electrode materials, such as transition metal disulfides [40] and MXenes [41,42], normally display higher capacitance values in acidic electrolytes than in neutral and alkaline electrolytes. Therefore, we took the protons as the objects to explore the ion chemisorption-induced pseudocapacitance. For the alkaline or neutral electrolyte ions, the mechanism could be similar.

In terms of the charge transfer amount, $\mathrm{H}$ adsorption concentrations of $\sim 20 \%-100 \%$ were covered to obtain the pseudocapacitances of pristine and defective $\mathrm{TiO}_{2}$. The charge state changes of the $\mathrm{Ti}$ atoms with increasing hydrogen adsorption concentration are listed in Table S5. For the case of fully covered hydrogen, an individual titanium atom enabled the storage of $0.3 \mathrm{e}$. As shown in Fig. $4 \mathrm{a}$, the number of charges, $\Delta Q$, transferred from the electrode surface to the hydrogen ions was linearly correlated with the $\mathrm{H}$ coverage.

In contrast to those of the pristine $\mathrm{TiO}_{2}$, the linear slopes of the defective $\mathrm{TiO}_{2}$ were large when the $\mathrm{H}$ coverage surpassed $50 \%$. The defective structures increased the number of active sites and thus the hydrogen ion storage. In principle, the valence of the host element would vary for proton adsorption. Therefore, spectrum techniques such as XPS enable the detection of such peak shifts. For example, the $\mathrm{Ti}^{3+} / \mathrm{Ti}^{4+}$ ratio obtained by fitting 

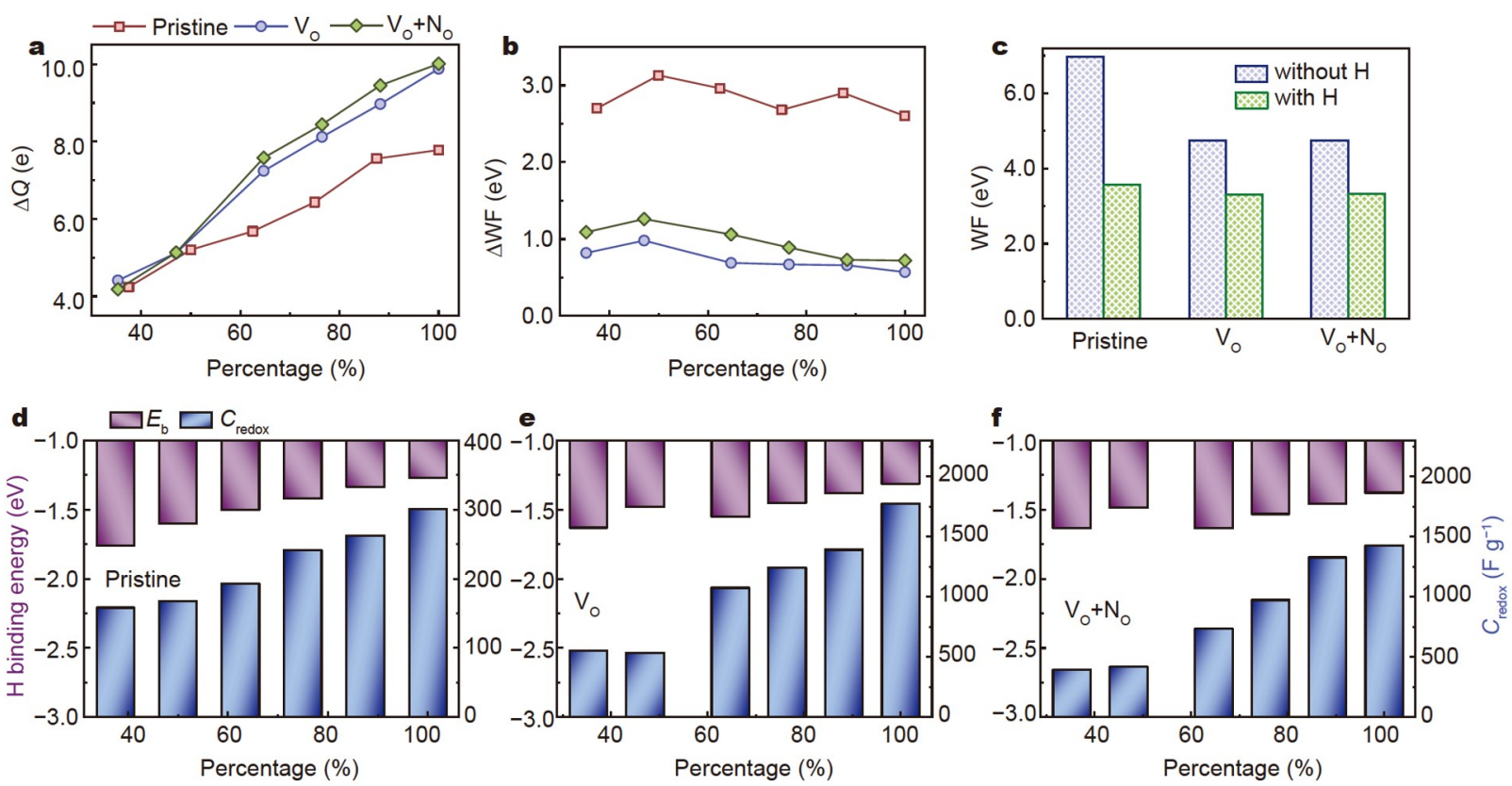

Figure 4 Charge storage and pseudocapacitances of pristine and defective $\mathrm{TiO}_{2}$. (a) $\Delta Q$ and (b) $\Delta \mathrm{WF}$ before and after $\mathrm{H}$ was adsorbed on $\mathrm{TiO}_{2}$ with and without defects. (c) WFs of neutrally charged pristine and defective $\mathrm{TiO}_{2}$ before and after $\mathrm{H}$ was fully adsorbed. (d-f) $\mathrm{H}$ binding energies and pseudocapacitances $\left(C_{\text {redox }}\right)$ of pristine $\mathrm{TiO}_{2}(101), \mathrm{TiO}_{2}-\mathrm{V}_{\mathrm{O}}$, and $\mathrm{TiO}_{2}-\mathrm{V}_{\mathrm{O}}+\mathrm{N}_{\mathrm{O}}$, respectively.

the XPS of the discharged electrode deduced the amount of charge storage per $\mathrm{TiO}_{2}$ [17]. With the RBA method, we calculated herein the variations of work function $(\triangle \mathrm{WF})$ (Fig. $4 \mathrm{~b}$ ). In contrast to the pristine $\mathrm{TiO}_{2}$ with relatively large changes of $\Delta \mathrm{WF}$, the defective $\mathrm{TiO}_{2}$ with different $\mathrm{H}$ coverages showed fluctuations of $\Delta \mathrm{WF}$ less than $\sim 0.4 \mathrm{eV}$. As observed in Fig. $4 \mathrm{c}$, the defective $\mathrm{TiO}_{2}$ displayed smaller WFs, i.e., $6.97 \mathrm{eV}$ (reported value is $6.99 \mathrm{eV}$ ) [43], 4.74, and $4.75 \mathrm{eV}$, for the pristine $\mathrm{TiO}_{2}$, $\mathrm{TiO}_{2}-\mathrm{V}_{\mathrm{O}}$, and $\mathrm{TiO}_{2}-\mathrm{V}_{\mathrm{O}}+\mathrm{N}_{\mathrm{O}}$ without $\mathrm{H}$ adsorption, respectively (Fig. S8). Fundamentally, the decrease of the WF stemmed from the extra electrons on the surface after the introduction of the defects.

According to the calculations of the above electronic structures and the charge transfer amount of $\mathrm{H}$, the pseudocapacitances $(C)$ of the pristine and defective $\mathrm{TiO}_{2}$ were obtained (Fig. $4 \mathrm{~d}-\mathrm{f}$ ) using the formula $C=\Delta Q / \Delta V$, Where $\Delta Q$ and $\Delta V$ are the charge difference and the change in electrode potential before and after hydrogen adsorption, respectively. As the $\mathrm{H}$ adsorption concentration increased, the pseudocapacitances of the three models showed an increasing tendency. As $\triangle \mathrm{WF}$ was basically unchanged or decreased when the hydrogen concentration increased (Fig. S9), the enhancement of the pseudocapacitances was mainly attributed to the increased charge storage rather than the WF variations. When the adsorption capacity of the hydrogen ions reached $100 \%$, the maximum gravimetric capacitance value of the pristine $\mathrm{TiO}_{2}$ reached $301 \mathrm{~F} \mathrm{~g}^{-1}$. By contrast, the pseudocapacitances of $\mathrm{TiO}_{2}$ with $\mathrm{V}_{\mathrm{O}}$ and $\mathrm{V}_{\mathrm{O}}+\mathrm{N}_{\mathrm{O}}$ rose to 1774 and $1426 \mathrm{Fg}^{-1}$, respectively. The capacitance difference between the $\mathrm{V}_{\mathrm{O}}$ and $\mathrm{V}_{\mathrm{O}}+\mathrm{N}_{\mathrm{O}}$ systems could be explained from a detailed WF perspective. The corresponding WF with $\mathrm{V}_{\mathrm{O}}+\mathrm{N}_{\mathrm{O}}$ decreased less than that with $\mathrm{V}_{\mathrm{O}}$, thereby resulting in a large voltage variation because of the high $\mathrm{V}_{\mathrm{O}}+\mathrm{N}_{\mathrm{O}}$ defect states above the $E_{\mathrm{F}}$. Therefore, defect $\mathrm{V}_{\mathrm{O}}$ showed a relatively high capacitive value when only $\mathrm{H}$ adsorption and the corresponding $\triangle \mathrm{WF}$ were considered.
Although the local charge transfer-induced pseudocapacitance of $\mathrm{TiO}_{2}-\mathrm{V}_{\mathrm{O}}$ was higher than that of $\mathrm{TiO}_{2}-\mathrm{V}_{\mathrm{O}}+\mathrm{N}_{\mathrm{O}}$, the practical pseudocapacitance should also include ion bonding strength and ion migrations on the surface. In principle, neither too strong nor too weak bonds between the electrode surface and the electrolyte ion are helpful in gaining high capacitive performance. On the one hand, excessively strong binding energy prevents hydrogen ions from migrating; on the other hand, excessively weak bonds hinder charge storage.

A previous study [25] revealed that binding energy in the range of $0.5-5.0 \mathrm{eV}$ is favorable for ion binding and migration. In our work (Fig. $4 \mathrm{~d}-\mathrm{f}$ ), the $\mathrm{H}$ binding energy varied from 1.3 to $1.6 \mathrm{eV}$. As the adsorption amount of hydrogen atoms increased, the binding strength gradually decreased because of the repulsion among $\mathrm{H}$ ions (Fig. S10). In general, such a moderate bonding strength is favorable for the simultaneous enhancement of charge storage and $\mathrm{H}$ migration.

\section{$\mathrm{H}$ migration on pristine and defective $\mathrm{TiO}_{2}$}

As mentioned previously, $\mathrm{H}$ tends to moderately bond on surfaces and thus shows great promise in the application of capacitive electrode materials. However, the sole consideration of H's surface adsorption is not enough to evaluate the material's overall capacitive property. In fact, the total charge storage amount is determined not only by $\mathrm{H}$ adsorption from the top surface but also by the sublayers. Intuitively, the sublayer $\mathrm{H}$ originates and migrates from the top surface. Therefore, $\mathrm{H}$ migration could be crucial to determine the total amount of $\mathrm{H}$ adsorption and thus the total charge storage. In other words, excellent electrode materials should be able to realize the facile migration of electrolyte ions to achieve large charge storage [4446].

For the $\mathrm{TiO}_{2}$ electrode, Fig. 5a shows three possible diffusion paths of one $\mathrm{H}$ ion from the top surface to the subsurface. The migration barrier was obtained through the CI-NEB method. 
Our calculations revealed that on the pristine $\mathrm{TiO}_{2}$ (101) surface, following path $\mathrm{A}, \mathrm{O} 5-\mathrm{O} 11, \mathrm{H}$ migrated from the surface $\mathrm{O}$ to the sublayer requiring energy as high as $2.25 \mathrm{eV}$ (Fig. 5b). The further introduction of defects significantly reduced the $\mathrm{H}$ migration barrier through paths $\mathrm{A}$ and $\mathrm{B}$ (O5-O9). Relative to the large barrier of pristine $\mathrm{TiO}_{2}$, the barriers of the defective structures with $\mathrm{V}_{\mathrm{O}}$ and $\mathrm{V}_{\mathrm{O}}+\mathrm{N}_{\mathrm{O}}$ on path $\mathrm{A}$ could drop to 1.54 and $0.73 \mathrm{eV}$, respectively. The $\mathrm{H}$ diffusion barrier in $\mathrm{TiO}_{2}-\mathrm{V}_{\mathrm{O}}+\mathrm{N}_{\mathrm{O}}$ was the lowest because of its smallest charge variation during the transfer from the initial state to the final one (Fig. S11). For path $\mathrm{C}(\mathrm{O} 6-\mathrm{O} 12)$, which was similar to path $\mathrm{A}$, the migration process could be difficult as the calculated barrier was $\sim 2 \mathrm{eV}$ (Figs S12 and S13), which was close to that of the pristine $\mathrm{TiO}_{2}$. On path $\mathrm{B}$, hydrogen migrated from $\mathrm{O} 5$ to the oxygen vacancy, and the barriers of the two defective structures were close $(\sim 0.6 \mathrm{eV}$, Figs S14 and S15). Therefore, the defects played a key role in suppressing the migration barriers. Fundamentally, either $\mathrm{V}_{\mathrm{O}}$ or $\mathrm{V}_{\mathrm{O}}+\mathrm{N}_{\mathrm{O}}$ introduced $\mathrm{n}$-type doping, thus causing the surface to be rich in electrons. Such an environment provided electrons to the surface oxygen atoms so that the polarized covalent $\mathrm{H}-\mathrm{O}$ bond strength was reduced. On the basis of the Brønsted-EvansPolanyi relations, the $\mathrm{H}$ migration barrier decreased accordingly. As shown in Fig. S16, no clear relationship was noted between binding energy and the diffusion barrier. The binding energies of $\mathrm{H}$ on the pristine and defective $\mathrm{TiO}_{2}$ were in the range of 1.0 $1.6 \mathrm{eV}$. Such small binding energy resulted in the corresponding small diffusion barrier, which ensured the migration of hydrogen ions from the surface to the subsurface. As a result, the total $\mathrm{H}$ adsorption amount could increase to achieve high capacitive performance.

According to the previous discussion about pseudocapacitance, the $\mathrm{V}_{\mathrm{O}}$ and $\mathrm{V}_{\mathrm{O}}+\mathrm{N}_{\mathrm{O}}$ systems indicated high capacitive values of about $1700 \mathrm{Fg}^{-1}$ when $\mathrm{H}$ coverage reached $100 \%$. However, the $\mathrm{H}$ migration results revealed that $\mathrm{H}$ showed a much lower migration barrier in the presence of $\mathrm{V}_{\mathrm{O}}+\mathrm{N}_{\mathrm{O}}$ than in the presence of $\mathrm{V}_{\mathrm{O}}$. Given the large barrier $\left(\mathrm{V}_{\mathrm{O}}: 1.54 \mathrm{eV}\right)$, the $\mathrm{V}_{\mathrm{O}}$ system could not easily achieve $100 \% \mathrm{H}$ coverage. By combining these two factors, we found that the defect $\mathrm{V}_{\mathrm{O}}+\mathrm{N}_{\mathrm{O}}$ could be superior to $\mathrm{V}_{\mathrm{O}}$ in terms of improving pseudocapacitance.

\section{Influence of band bending on electron transfer}

In a practical capacitive process, the adsorption and migration of electrolyte ions and electron transfer play key roles in essentially determining the overall capacitance. Band bending is known to exert greater influence on 3D materials than on low-dimensional materials, such as graphene-derived materials and MXenes. To date, most explorations have disregarded the electron transmission process. Thus, the current understanding of electrode materials could be misleading in terms of material design and screening. As a matter of fact, when semiconductive electrode materials interface with aqueous electrolytes or metallic contacts, band bending occurs because of the carrier recombination (Fig. 6a) at interfaces. As a result, the electron travel in the electrode materials could be severely prohibited. Taking n-type $\mathrm{TiO}_{2}$ as an example, the band upbends in the space charge region (Fig. 6b). The upbending CB forms a quadratic barrier for the electron transfer from the bulk to the surface. The barrier height and width are fundamentally governed by material dielectric properties and defect dopant concentrations (further details are available in the Supplementary information). The flat band potential and carrier concentration could be obtained through Mott-Schottky analysis. Reports have shown that carrier concentration for $\mathrm{TiO}_{2}$ nanotube arrays is $10^{18} \mathrm{~cm}^{-3}$ according to Mott-Schottky plots [47]. Basically, the higher and
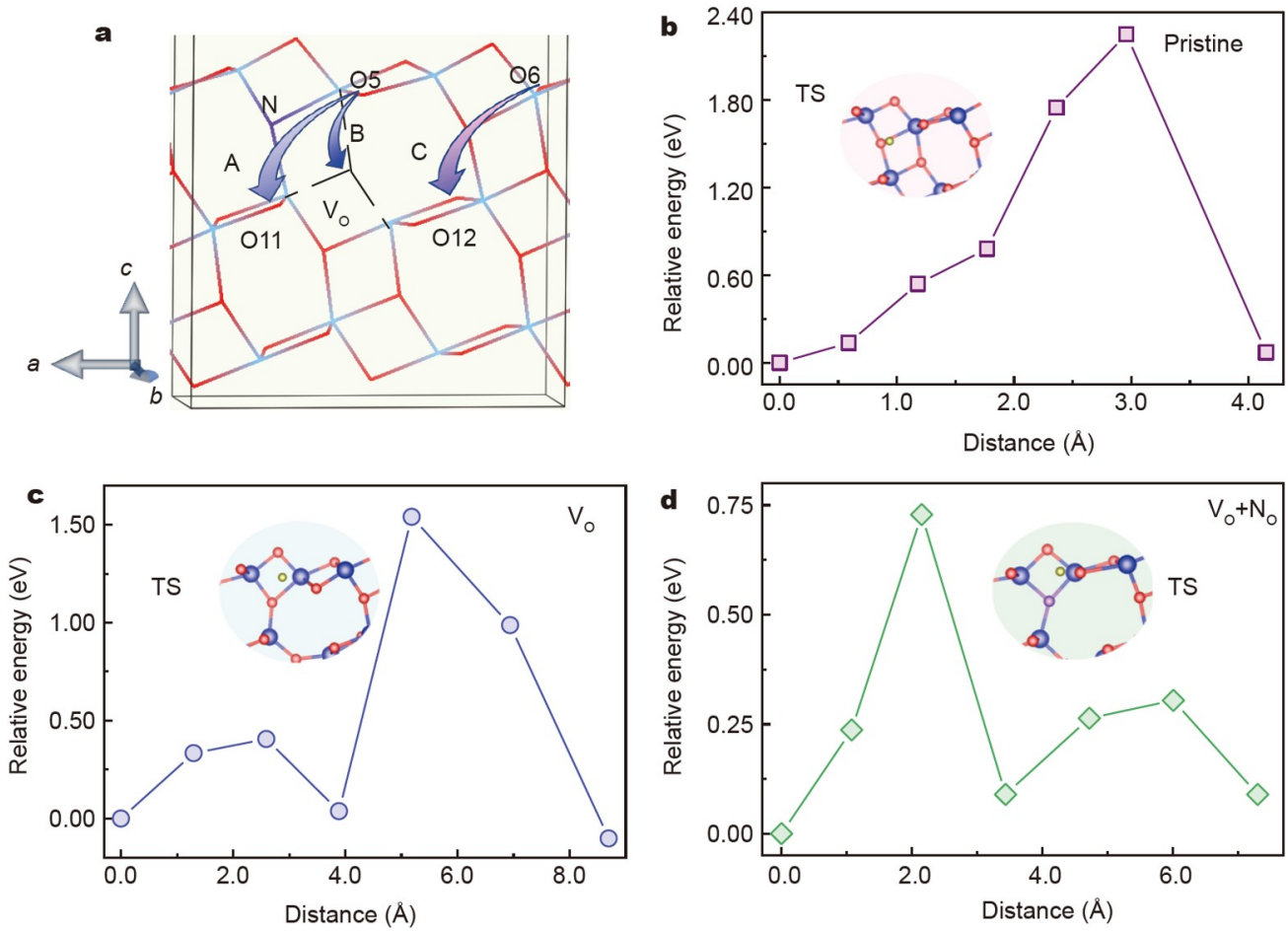

Figure 5 Hydrogen migration paths and barriers in pristine and defective $\mathrm{TiO}_{2}$. (a) Schematic map of migration path of $\mathrm{H}$ near the defect. The three paths $\mathrm{A}$, $\mathrm{B}$, and $\mathrm{C}$ represent the migration of hydrogen from $\mathrm{O} 5$ to $\mathrm{O} 11, \mathrm{O} 5$ to $\mathrm{O} 9$, and $\mathrm{O} 6$ to $\mathrm{O} 12$, respectively. Hydrogen migration paths and corresponding energy barriers from $\mathrm{O} 5$ to $\mathrm{O} 11$ (path $\mathrm{A}$ ) in (b) pristine $\mathrm{TiO}_{2}$, (c) $\mathrm{TiO}_{2}-\mathrm{V}_{\mathrm{O}}$, and (d) $\mathrm{TiO}_{2}-\mathrm{V}_{\mathrm{O}}+\mathrm{N}_{\mathrm{O}}$. 

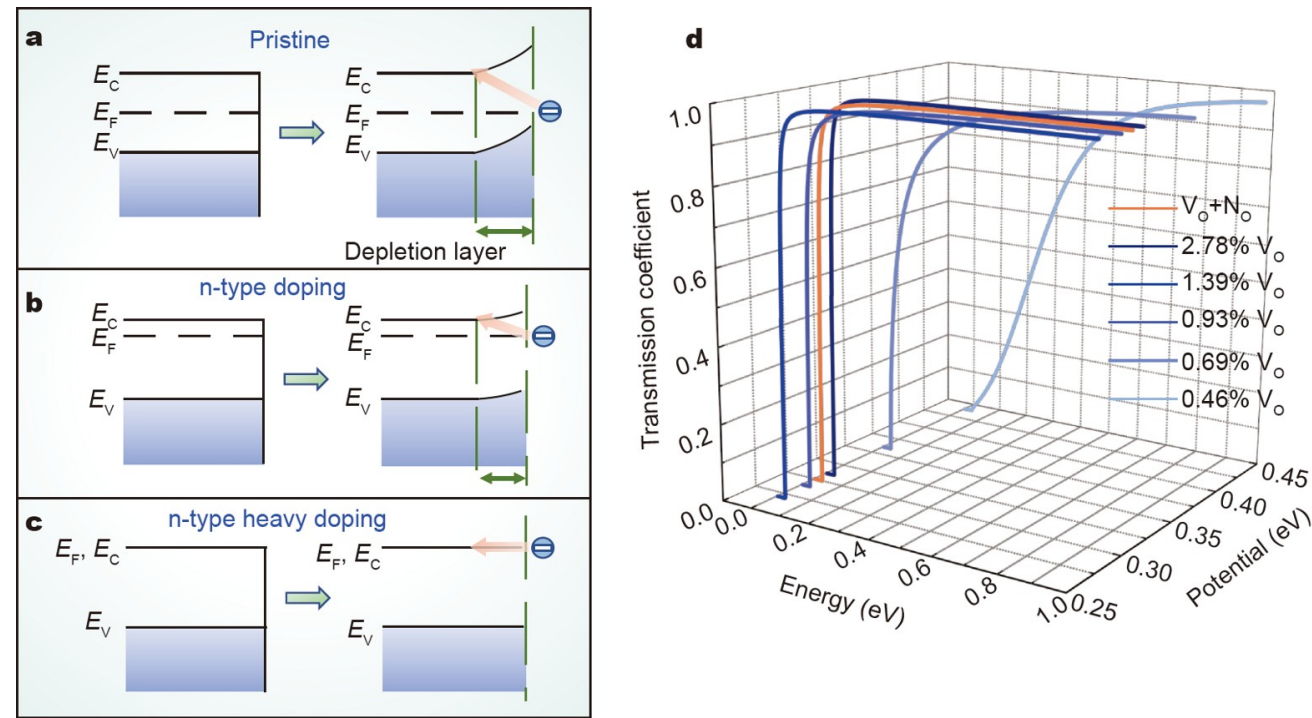

Figure 6 Schematic of surface band scheme and transmission coefficients of $\mathrm{TiO}_{2}$. Schematic of surface band schemes of (a) pristine, (b) n-type doping, and (c) n-type heavy doping systems. (d) Transmission coefficients of defective $\mathrm{TiO}_{2}$ versus incident energy of electrons and the potential barriers of band bending.

the wider the barrier is, the lower the electron tunneling coefficient will be from bulk to the surface or vice versa. Therefore, a small barrier is always required for a given electrode material with excellent performance.

To calculate the width and height of the bending band and thus gain the barrier properties, we chose the effective mass $m_{\mathrm{n}}{ }^{*}$ $=0.0468 m_{0}$ and $m_{\mathrm{p}}{ }^{*}=0.6614 m_{0}$ for further investigations, where $m_{\mathrm{n}}{ }^{*}, m_{\mathrm{p}}{ }^{*}$ and $m_{0}$ are the effective mass of electrons, the effective mass of holes, and the rest mass of electrons, respectively. The carrier concentrations of the pristine $\mathrm{TiO}_{2}, \mathrm{TiO}_{2}-\mathrm{V}_{\mathrm{O}}$, and $\mathrm{TiO}_{2}-$ $\mathrm{V}_{\mathrm{O}}+\mathrm{N}_{\mathrm{O}}$ were calculated to be $5.09 \times 10^{-10}, 5.31 \times 10^{21}$, and $2.66 \times$ $10^{21} \mathrm{~cm}^{-3}$, respectively (detailed calculations in the Supplementary information). We note that the pristine carrier concentration was 30 orders of magnitude smaller than that of the system with defects. Meanwhile, the width of the space charge region of the defective $\mathrm{TiO}_{2}$ significantly decreased to the order of angstroms, thereby making the charge transfer feasible. In terms of barrier height, it is actually determined by dopant concentrations. A large dopant concentration leads to minimal band bending and a small barrier height. When the material is heavily doped, the $E_{\mathrm{F}}$ could reach the $\mathrm{CB}$ (Fig. 6c). Consequently, the material becomes conductive in the process known as semiconductor degeneracy.

In this study, the probability of electron transfer at the interface was assessed. Specifically, we calculated the transmission coefficients of electrons in several defective $\mathrm{TiO}_{2}$, i.e., $\mathrm{TiO}_{2}-$ $\mathrm{V}_{\mathrm{O}}+\mathrm{N}_{\mathrm{O}}$ and $\mathrm{TiO}_{2}$ with various $\mathrm{V}_{\mathrm{O}}$ concentrations, to mimic realistic doping environments (Fig. $6 \mathrm{~d}$ ) by using the developed TMM. The defect concentrations, which are shown as blue curves from dark to light in Fig. 6d, provided a comprehensive picture of the effects of the defects on the carrier transmission. The most stable oxygen vacancy configurations in the structures with different defect concentrations were observed on the subsurface layer, as shown by the O9 position in Fig. 2a. The energy differences for the other surface locations are listed in Table S6. For the defective structures with oxygen vacancy concentrations higher than $0.69 \%$, the transmission coefficients rapidly reached $99 \%(\sim 0.39 \mathrm{eV})$. For the case of the $\mathrm{V}_{\mathrm{O}}$ concentration lower than $0.46 \%$ (within $1.0 \mathrm{eV}$ ), the transmission was lower than $98 \%$. As the defect content increased up to $0.69 \%$, the transmission increased slowly to $99 \%$ within $0.93 \mathrm{eV}$. Such variation could be extended to the $\mathrm{TiO}_{2}-\mathrm{V}_{\mathrm{O}}+\mathrm{N}_{\mathrm{O}}$ system.

Transmission is essentially decided by the shape of the barrier (i.e., $\mathrm{CB}$ bending) and the initial kinetic energy. The former factor was fixed herein because its shape was only controlled by the dopants of the materials. The latter one could change on the basis of extrinsic conditions, such as the variation of the electric double layer (EDL) field.

To obtain a reasonable energy range of electrons and transmission coefficients, we considered the influence of applied voltage and the EDL field. The applied voltage was assumed to be the threshold voltage of aqueous electrolytes (i.e., $1.23 \mathrm{~V}$ ) that caused electrons to gather on the $\mathrm{H}$ ion side of the EDL. Under a voltage of $1.23 \mathrm{~V}$, the electron gained kinetic energy of $1.23 \mathrm{eV}$. As the EDL pointed inside, the electrons at the surface could be suppressed during the transfer from the surface to the sublayers. Quantitatively, the kinetic energy lost in the EDL was calculated through the formula $W=e \times E \times d$, where $e$ is the elementary charge, $E$ is the electric field intensity of $\sim 1 / 3 \mathrm{~V} \AA^{-1}$ and $d$ is the charge transfer length of $\sim 1 \AA$. In sum, the kinetic energy remained at $\sim 0.9 \mathrm{eV}$ at the band bending surface. Therefore, energy of $0.9 \mathrm{eV}$ was set as the theoretical kinetic energy limit.

To mimic all the possible practical electron kinetic energy, we varied the energy from 0 to $1.0 \mathrm{eV}$ and then calculated the corresponding transmission coefficient from the sublayers to the top surface. For the energy limit of $0.9 \mathrm{eV}$, the transmission coefficient of the structure with the lowest doping concentration reached $97 \%$. In other words, an energy barrier for electron travel at the surface region was almost nonexistent.

In practice, kinetic energy could be rather lower than the theoretical limit of $0.9 \mathrm{eV}$. As shown in Fig. 5d, the transmission efficiency rapidly decreased for the systems with low defect concentrations. In addition, the $\mathrm{V}_{\mathrm{O}}$ and $\mathrm{V}_{\mathrm{O}}+\mathrm{N}_{\mathrm{O}}$ defective structures showed similar electron transmission behaviors. Therefore, electron travel in defective systems rather than pristine systems is not an issue, and their pseudocapacitance values generated by the charge storage of $\mathrm{H}$ ions could be realized to a large extent. 


\section{Total capacitance of pristine and defective $\mathrm{TiO}_{2}$}

The total capacitance of $\mathrm{TiO}_{2}$ was calculated according to the connection between the quantum capacitance and the EDL capacitance in series and then according to the parallel connection with pseudocapacitance $[48,49]$. For the EDL capacitance $\left(C_{\mathrm{EDL}}\right)$, the values of the pristine and defective $\mathrm{TiO}_{2}$ calculated according to the formula $C_{\mathrm{EDL}}=\varepsilon_{0} \varepsilon_{\mathrm{r}} / d$ were $\sim 47$ and $48 \mathrm{~F} \mathrm{~g}^{-1}$, respectively. $\varepsilon_{0}$ and $\varepsilon_{\mathrm{r}}$ are the vacuum dielectric constant and the dielectric constant of the electrolyte solution, respectively. $d$ is the width of the Helmholtz layer. In the series with quantum capacitance (Fig. S17), the combination of the EDL and quantum capacitance values decreased to 33 and $47 \mathrm{~F} \mathrm{~g}^{-1}$ for the pristine and defective $\mathrm{TiO}_{2}$, respectively. By adding up their capacitances, we obtained the total capacitances of the three $\mathrm{TiO}_{2}$ structures as $334 \mathrm{~F} \mathrm{~g}^{-1}$ (pristine), $1821 \mathrm{~F} \mathrm{~g}^{-1}\left(\mathrm{TiO}_{2}-\mathrm{V}_{\mathrm{O}}\right)$, and $1473 \mathrm{Fg}^{-1}\left(\mathrm{TiO}_{2}-\mathrm{V}_{\mathrm{O}}+\mathrm{N}_{\mathrm{O}}\right)$, respectively. Obviously, the pseudocapacitance made a major contribution to the total capacitance.

The calculated capacitance of pristine $\mathrm{TiO}_{2}$ was 16 times that of the experimental value $\left(\sim 20 \mathrm{~F} \mathrm{~g}^{-1}\right)$ [18]. The large difference stemmed from the high hydrogen migration barrier and the difficulty of electron transport. By contrast, the difference between the theoretical values and the experimental results of the defective structures was significantly small. As the defective $\mathrm{TiO}_{2}$ significantly reduced the ion migration barrier and facilitated the electron transport, the pseudocapacitance could ultimately be achieved [18].

In conclusion, charge storage capacity, ion migration, and electron transfer should be comprehensively considered to evaluate efficient electrode materials. In $\mathrm{TiO}_{2}$ cases, although defects largely improve charge storage, the reduction of ion migration barriers and electron transmission is strongly required to essentially achieve high capacitance. As demonstrated in this work, the defect $\mathrm{V}_{\mathrm{O}}+\mathrm{N}_{\mathrm{O}}$ was more advantageous than $\mathrm{V}_{\mathrm{O}}$. Through this work, we provide a route for the design of effective electrode materials via the simultaneous consideration of charge storage capacity, ion migration, and electron dynamics transfer.

\section{CONCLUSIONS}

From the perspectives of charge storage, electrolyte ion diffusion, and electron transfer of electrode materials, we systematically investigated the origin of the capacitances of pristine and defective $\mathrm{TiO}_{2}$ and discovered the key role of defects in the production of high capacitances by using first-principle calculations and TMM. Using the $\mathrm{H}$ ion insertion model, we calculated the maximum capacitances as $334 \mathrm{Fg}^{-1}$ (pristine), $1821 \mathrm{Fg}^{-1}\left(\mathrm{~V}_{\mathrm{O}}\right)$, and $1473 \mathrm{Fg}^{-1}\left(\mathrm{~V}_{\mathrm{O}}+\mathrm{N}_{\mathrm{O}}\right)$, respectively. In particular, $\mathrm{TiO}_{2}-\mathrm{V}_{\mathrm{O}}+\mathrm{N}_{\mathrm{O}}$ realized the theoretical capacitance value to a large extent in the experiments because of its small ionic migration barrier and favorable electron transport characteristics. This work provides theoretical guidance for improving the performance of semiconductor electrode materials and proposes a comprehensive design role to regulate the capacitance performance of supercapacitor electrode materials.

\section{Received 22 May 2021; accepted 30 June 2021; published online 30 August 2021}

1 Pomerantseva E, Bonaccorso F, Feng X, et al. Energy storage: the future enabled by nanomaterials. Science, 2019, 366: eaan 8285

2 Choi C, Ashby DS, Butts DM, et al. Achieving high energy density and high power density with pseudocapacitive materials. Nat Rev Mater, 2019, 5: 5-19
3 Jiang Y, Liu J. Definitions of pseudocapacitive materials: a brief review. Energy Environ Mater, 2019, 2: 30-37

4 Nguyen T, Montemor MF. Metal oxide and hydroxide-based aqueous supercapacitors: From charge storage mechanisms and functional electrode engineering to need-tailored devices. Adv Sci, 2019, 6: 1801797

5 Chen Y, Hao X, Chen GZ. Nanoporous versus nanoparticulate carbonbased materials for capacitive charge storage. Energy Environ Mater, 2020, 3: 247-264

6 Liu T, Zhou Z, Guo Y, et al. Block copolymer derived uniform mesopores enable ultrafast electron and ion transport at high mass loadings. Nat Commun, 2019, 10: 675

7 Tian K, Wang J, Cao L, et al. Single-site pyrrolic-nitrogen-doped $\mathrm{sp}^{2}$ hybridized carbon materials and their pseudocapacitance. Nat Commun, 2020, 11: 3884

8 Yan J, Wang Q, Wei T, et al. Recent advances in design and fabrication of electrochemical supercapacitors with high energy densities. Adv Energy Mater, 2014, 4: 1300816

9 Zhang Z, Yates Jr. JT. Band bending in semiconductors: chemical and physical consequences at surfaces and interfaces. Chem Rev, 2012, 112: 5520-5551

10 Jiang C, Moniz SJA, Wang A, et al. Photoelectrochemical devices for solar water splitting-materials and challenges. Chem Soc Rev, 2017, 46: $4645-4660$

11 Augustyn V, Simon P, Dunn B. Pseudocapacitive oxide materials for high-rate electrochemical energy storage. Energy Environ Sci, 2014, 7: 1597-1614

12 Wang R, Hashimoto K, Fujishima A, et al. Light-induced amphiphilic surfaces. Nature, 1997, 388: 431-432

13 Fujishima A, Honda K. Electrochemical photolysis of water at a semiconductor electrode. Nature, 1972, 238: 37-38

14 Chen $\mathrm{X}$, Liu L, Huang F. Black titanium dioxide $\left(\mathrm{TiO}_{2}\right)$ nanomaterials. Chem Soc Rev, 2015, 44: 1861-1885

15 Nguyen T, Li J, Lizundia E, et al. Black titania with nanoscale helicity. Adv Funct Mater, 2019, 29: 1904639

16 Chen X, Liu L, Yu PY, et al. Increasing solar absorption for photocatalysis with black hydrogenated titanium dioxide nanocrystals. Science, 2011, 331: 746-750

17 Zhi J, Cui H, Wang Z, et al. Surface confined titania redox couple for ultrafast energy storage. Mater Horiz, 2018, 5: 691-698

18 Wang X, Yuan X, Wang D, et al. Tunable synthesis of colorful nitrogen-doped titanium oxide and its application in energy storage. ACS Appl Energy Mater, 2018, 1: 876-882

19 Huang F, Wang Z, Yang C. Titanium Oxide-based Supercapacitor Electrode Material and Method of Manufacturing Same. United States Patent, 10192690B2, 2019-01-29

20 Li Q, Xia Z, Wang S, et al. The preparation and characterization of electrochemical reduced $\mathrm{TiO}_{2}$ nanotubes/polypyrrole as supercapacitor electrode material. J Solid State Electrochem, 2017, 21: 2177-2184

21 Yang C, Wang X, Dong W, et al. Nitrogen-doped black titania for high performance supercapacitors. Sci China Mater, 2020, 63: 1227-1234

22 El-Gendy DM, Abdel Ghany NA, Allam NK. Black titania nanotubes/ spongy graphene nanocomposites for high-performance supercapacitors. RSC Adv, 2019, 9: 12555-12566

23 Yao X, Chen L, Liu M, et al. Rational design of $\mathrm{Si} / \mathrm{TiO}_{2}$ heterojunction photocatalysts: Transfer matrix method. Appl Catal B-Environ, 2018, 221: 70-76

24 Brezesinski T, Wang J, Polleux J, et al. Templated nanocrystal-based porous $\mathrm{TiO}_{2}$ films for next-generation electrochemical capacitors. J Am Chem Soc, 2009, 131: 1802-1809

25 Wang L, Wang J, Zhang Z, et al. Origin of theoretical pseudocapacitance of two-dimensional supercapacitor electrodes $\mathrm{Ti}_{3} \mathrm{C}_{2} \mathrm{~T}_{2}(\mathrm{~T}=$ bare, O, S). J Mater Chem A, 2019, 7: 16231-16238

26 Zhang Z, Wu M, Wang L, et al. Exploring the microscopic mechanism of pseudocapacitance with electronic structures in monolayer $1 \mathrm{~T}-\mathrm{MoS}_{2}$ electrodes for supercapacitors. Mater Chem Front, 2019, 3: 1310-1316

27 Kresse G, Furthmüller J. Efficiency of ab-initio total energy calculations for metals and semiconductors using a plane-wave basis set. Comput 
Mater Sci, 1996, 6: 15-50

28 Perdew JP, Burke K, Ernzerhof M. Generalized gradient approximation made simple. Phys Rev Lett, 1996, 77: 3865-3868

29 Heyd J, Scuseria GE, Ernzerhof M. Hybrid functionals based on a screened Coulomb potential. J Chem Phys, 2003, 118: 8207-8215

30 Henkelman G, Arnaldsson A, Jónsson H. A fast and robust algorithm for Bader decomposition of charge density. Comput Mater Sci, 2006, 36: $354-360$

31 Tang W, Sanville E, Henkelman G. A grid-based Bader analysis algorithm without lattice bias. J Phys-Condens Matter, 2009, 21: 084204

32 Henkelman G, Uberuaga BP, Jónsson H. A climbing image nudged elastic band method for finding saddle points and minimum energy paths. J Chem Phys, 2000, 113: 9901-9904

33 Howard CJ, Sabine TM, Dickson F. Structural and thermal parameters for rutile and anatase. Acta Crystlogr B Struct Sci, 1991, 47: 462-468

34 Na-Phattalung S, Smith MF, Kim K, et al. First-principles study of native defects in anatase $\mathrm{TiO}_{2}$. Phys Rev B, 2006, 73: 125205

35 Nam Y, Lim JH, Ko KC, et al. Photocatalytic activity of $\mathrm{TiO}_{2}$ nanoparticles: a theoretical aspect. J Mater Chem A, 2019, 7: 13833-13859

36 Cheng H, Selloni A. Surface and subsurface oxygen vacancies in anatase $\mathrm{TiO}_{2}$ and differences with rutile. Phys Rev B, 2009, 79: 092101

37 Wang Q, He H, Luan J, et al. Synergistic effect of N-doping and rich oxygen vacancies induced by nitrogen plasma endows $\mathrm{TiO}_{2}$ superior sodium storage performance. Electrochim Acta, 2019, 309: 242-252

38 Kang J, Wei SH, Zhu K, et al. First-principles theory of electrochemical capacitance of nanostructured materials: Dipole-assisted subsurface intercalation of lithium in pseudocapacitive $\mathrm{TiO}_{2}$ anatase nanosheets. J Phys Chem C, 2011, 115: 4909-4915

39 Zhan C, Naguib M, Lukatskaya M, et al. Understanding the MXene pseudocapacitance. J Phys Chem Lett, 2018, 9: 1223-1228

40 Acerce M, Voiry D, Chhowalla M. Metallic 1T phase $\mathrm{MoS}_{2}$ nanosheets as supercapacitor electrode materials. Nat Nanotech, 2015, 10: 313-318

41 Ghidiu M, Lukatskaya MR, Zhao MQ, et al. Conductive two-dimensional titanium carbide 'clay' with high volumetric capacitance. Nature, 2014, 516: 78-81

42 Li J, Yuan X, Lin C, et al. Achieving high pseudocapacitance of 2D titanium carbide (MXene) by cation intercalation and surface modification. Adv Energy Mater, 2017, 7: 1602725

43 Zhang AY, Wang WY, Chen JJ, et al. Epitaxial facet junctions on $\mathrm{TiO}_{2}$ single crystals for efficient photocatalytic water splitting. Energy Environ Sci, 2018, 11: 1444-1448

$44 \mathrm{Xu} \mathrm{X}$, Zhao R, Ai W, et al. Controllable design of $\mathrm{MoS}_{2}$ nanosheets anchored on nitrogen-doped graphene: Toward fast sodium storage by tunable pseudocapacitance. Adv Mater, 2018, 30: 1800658

$45 \mathrm{Xu} \mathrm{X,} \mathrm{Zhao} \mathrm{R,} \mathrm{Chen} \mathrm{B,} \mathrm{et} \mathrm{al.} \mathrm{Progressively} \mathrm{exposing} \mathrm{active} \mathrm{facets} \mathrm{of} \mathrm{2D}$ nanosheets toward enhanced pseudocapacitive response and high-rate sodium storage. Adv Mater, 2019, 31: 1900526

46 Cui J, Yao S, Lu Z, et al. Revealing pseudocapacitive mechanisms of metal dichalcogenide $\mathrm{SnS}_{2}$ /graphene-CNT aerogels for high-energy $\mathrm{Na}$ hybrid capacitors. Adv Energy Mater, 2018, 8: 1702488

47 Zhang J, Wang Y, Wu J, et al. Remarkable supercapacitive performance of $\mathrm{TiO}_{2}$ nanotube arrays by introduction of oxygen vacancies. Chem Eng J, 2017, 313: 1071-1081

48 Conway BE. Transition from "supercapacitor" to "battery" behavior in electrochemical energy storage. J Electrochem Soc, 1991, 138: 15391548

49 Paek E, Pak AJ, Hwang GS. A computational study of the interfacial structure and capacitance of graphene in $[\mathrm{BMIM}]\left[\mathrm{PF}_{6}\right]$ ionic liquid. J Electrochem Soc, 2012, 160: A1-A10

Acknowledgements This work was financially supported by the National Key Research and Development Program (2016YFB0901600), Tianjin City Distinguished Young Scholar Fund (17JCJQJC45100), the National Natural Science Foundation of China (21975136 and 21573117), Tianjin Key Research and Development Program (18ZXSZSF00060), the Open Funds from the National Engineering Lab for Mobile Source Emission Control Technology (NELMS2018A01), and the project of Shenzhen Science, Technology and Innovation Committee (JCYJ20190808151603654).

Author contributions Wang L, Yao X, Wang WH and Wang WC designed the research. Wang $\mathrm{L}$ performed the first-principles calculations. Wang $\mathrm{L}$ and Wang WC wrote the manuscript with contributions from all other authors. All authors contributed to the discussion of the results.

Conflict of interest The authors declare that they have no conflict of interest.

Supplementary information Experimental details and supporting data are available in the online version of the paper.

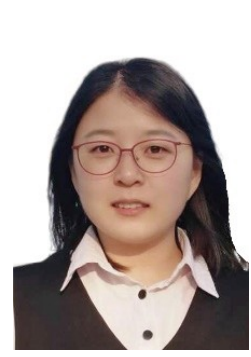

Lijing Wang is currently a $\mathrm{PhD}$ candidate in electronic science and engineering at Nankai University under the supervision of Prof. Weichao Wang. Her research focuses on the rational design of twodimensional MXenes and transition metal oxide electrode materials of supercapacitors through machine learning and first-principle calculations based on density functional theory.

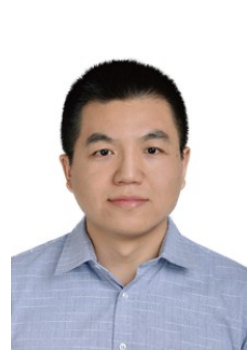

Xiaolong Yao received his $\mathrm{PhD}$ degree in electronic science and engineering from Nankai University in 2018. His research interests are computational condensed matter physics and computational materials science, including the simulation of excitation state dynamics in the external field, rational design and performance prediction of new catalytic materials based on oxides, rational design and functionalization of low-dimensional materials, and theoretical calculation of surface atomic processes and film growth.

Weichao Wang is a Professor of electrical and optical engineering at Nankai University in China. He received his $\mathrm{PhD}$ degree in materials science and engineering from The University of Texas at Dallas in 2011. He then worked at Nanostellar Inc. as a scientist (2011-2012) and transferred to Alpha Omega Semiconductor Inc. (2012) before joining the faculty of Nankai University in 2013. His research interests include electrochemical catalysts and heterogeneous oxide design.

\section{$\mathrm{TiO}_{2}$ 示例赝电容电极材料的设计规则: 离子吸附, 扩} 散和电子传输

王丽静 ${ }^{1 \dagger}$, 姚晓龙 ${ }^{1 \dagger}$, 陈达 ${ }^{2}$, 王瑾 ${ }^{1}$, 张振州 ${ }^{1}$, 刘洁宇 ${ }^{1}$, 林天全 $^{3}$, 王维华 ${ }^{1}$, 洪樟连 ${ }^{4}$, 黄富强 ${ }^{3}$, 王卫超 ${ }^{*}$

摘要 高性能噟电容的发展需要从电子转移、电解质离子吸附和扩散 方面全面理解电极材料. 本论文结合第一性原理与转移矩阵法, 以 $\mathrm{TiO}_{2}$ 为原型, 通过引入各种缺陷, 即氧缺陷 $\left(V_{O}\right)$ 和共掺杂缺陷 $\left(V_{O}+N_{O}\right)$, 在综 合考虑以上因素后获得了较高的赝电容. 与本征 $\mathrm{TiO}_{2}\left(300 \mathrm{~F} \mathrm{~g}^{-1}\right)$ 相比, 有缺陷的 $\mathrm{TiO}_{2}$ 产生的赝电容高达 $1700 \mathrm{~F} \mathrm{~g}^{-1}$. 此外, 缺陷会使得表面能带

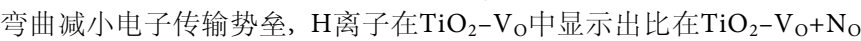
中高得多的势垒, 表明在共掺杂体系中 $\mathrm{H}$ 扩散更容易. 这项工作为电解 质离子的吸附和扩散以及缺陷对电子传输的影响提供了见解, 对于下 一代超级电容器电极材料的设计和优化具有重要意义. 